Author's post-print: A. Alonso-Estébanez, P. Pascual-Muñoz, Felipe P. Álvarez Rabanal, D. Castro-Fresno, J.J. Del Coz Díaz. "New System for the Acceleration of the Airflow in Wind Turbines". Recent Patents on Mechanical Engineering 12 (2019). DOI: $10.2174 / 2212797612666190311154747$.

\title{
New System for the Acceleration of the Airflow in Wind Turbines
}

Alejandro Alonso-Estébanez a,*, Pablo Pascual-Muñoz ${ }^{\text {b }}$, Felipe P. Alvarez Rabanal c ${ }^{\text {, Daniel Castro-Fresno }}{ }^{\text {b }}$, Juan J. Del Coz Díaz ${ }^{\mathrm{c}}$.

\footnotetext{
${ }^{a}$ Department of Transports, Projects and Process Technology, Industrial Engineering School, University of Cantabria, Avenida de los Castros 46, Santander 39005, Cantabria, Spain.

${ }^{b}$ Department of Transports, Projects and Processes Technology, Civil Engineering School, University of Cantabria, Avenida de los Castros 44, Santander 39005, Cantabria, Spain.

'Department of Construction, Polytechnique Engineering School, University of Oviedo, Campus de Viesques, Departmental Building 7, Gijón 33204, Asturias, Spain.
}

\section{Increasing the Airflow in Wind Turbines}

Abstract: Background: This patent is based on the wind industry technology calted Diffuser Augmented Wind Turbines (DAWTs). This technology consists of a horizontal axis wind turbine, which is housed inside a duct with diverging section in the direction of the free air stream. In this paper, a review of preceding patents related to this technology is carried out

Objective: This paper presents an innovative patent to improve the performance of horizontal axis wind turbines. In particular, this system is aimed at improving the performance of those turbines that otherwise might not be installed due to the low wind resource existing at certain locations.

Method: The most innovative elements of this patent are.(1) the semi-spherical grooves, which are mechanized on the surface of the two diffusers in order to guarantee a more energetic boundary layer; (2) the coaxial diffuser, which is located downwind following the first diffuser in order to increase the suction effect on the air mass close to the inlet; (3) the coaxial rings located around the first diffuser outlet, which are used to deflect the external airflow toward the turbine wake; and (4), the self-orientating system to orientate the system by the prevailing wind direction.

Results: An application of the patent for increasing the power generated by a horizontal axis wind turbine with three blades is presented. The patent is designed and its performance is evaluated by using a Computational Fluid Dynamics code. The numerical results show that this system rises the airflow going through the rotor of the turbine.

Conclusion: The patented device is an original contribution aimed at enabling a more profitable installation of wind turbines in places where the wind resource is insufficient because of the wind shear caused both by the proximity of the earth and the obstacles on the earth surface.

Keywords: Wind energy, Wind turbines, Wind lens technology, Diffuser, Flow accelerator, Computational fluid dynamics (CFD).

\section{Introduction}

Since the end of the $20^{\text {th }}$ century, some governments around the world have promoted new policies to stimulate the development and use of renewable energies [1,2,3]. This has been mainly due to three reasons: the depletion of fossil fuels, the increase of energy demand and the environmental problems arising from using fossil fuels as energy source $[4,5,6]$. Regarding the environmental problems, two of the today's greatest concerns are the global warming and the higher level of atmospheric pollution, as they negatively affect the survival of our species. For all these reasons, different technologies have been developed over the last decades and are being used nowadays $[7,8,9]$. These technologies are commonly classified according to the type of energy source used by them: sun, wind, water, etc. Among these renewable energies, the wind energy is at the second place in terms of the renewable power generation capacity worldwide (Fig. 1). In fact, this energy shows an increasing trend between 2011 and 2017 [10, 11].

* Corresponding author.

E-mail addresses: alejandro.alonso@unican.es (A. Alonso-Estébanez).

Tel: +34942200894 
The number of onshore locations where to install a wind farm profitably has decreased in the last decade due to the continuous building of wind farms $[12,13]$. This circumstance motivated the developing of offshore wind farms. However, these types of farms still have several issues to be dealt with such as the high cost of building and maintenance, the huge visual impact caused by them and the water depth limitation for the construction of the farm $[14,15,16]$. Accordingly, some researchers proposed other locations to take advantage of the wind resource such as roadsides of highways $[17,18]$ or specific spots in urban environments where the wind velocity increases $[19,20,21]$. In this case, the acceleration of the airflow is caused by the presence of buildings, which narrows the streamlines while flowing between them [22]. The acceleration of the airflow is also due to the thermal gradients existing in the city environment. Nevertheless, the mean airflow in most of urban areas is quite low because of an increase in the aerodynamic roughness $[23,24]$. As the power generated by wind turbines rises with the cube of wind velocity, the reduction of wind speed in urban areas generally makes the local authorities to discard the integration of the wind technology in cities. In addition, within urban areas the airflow is characterized by a high level of turbulence, which contributes to $15 \%-30 \%$ reduction in the output power of the turbine [25]. This has stimulated the development of new techniques aimed at improving the turbine efficiency in locations with an insufficient wind resource [26, 27, 28, 29].

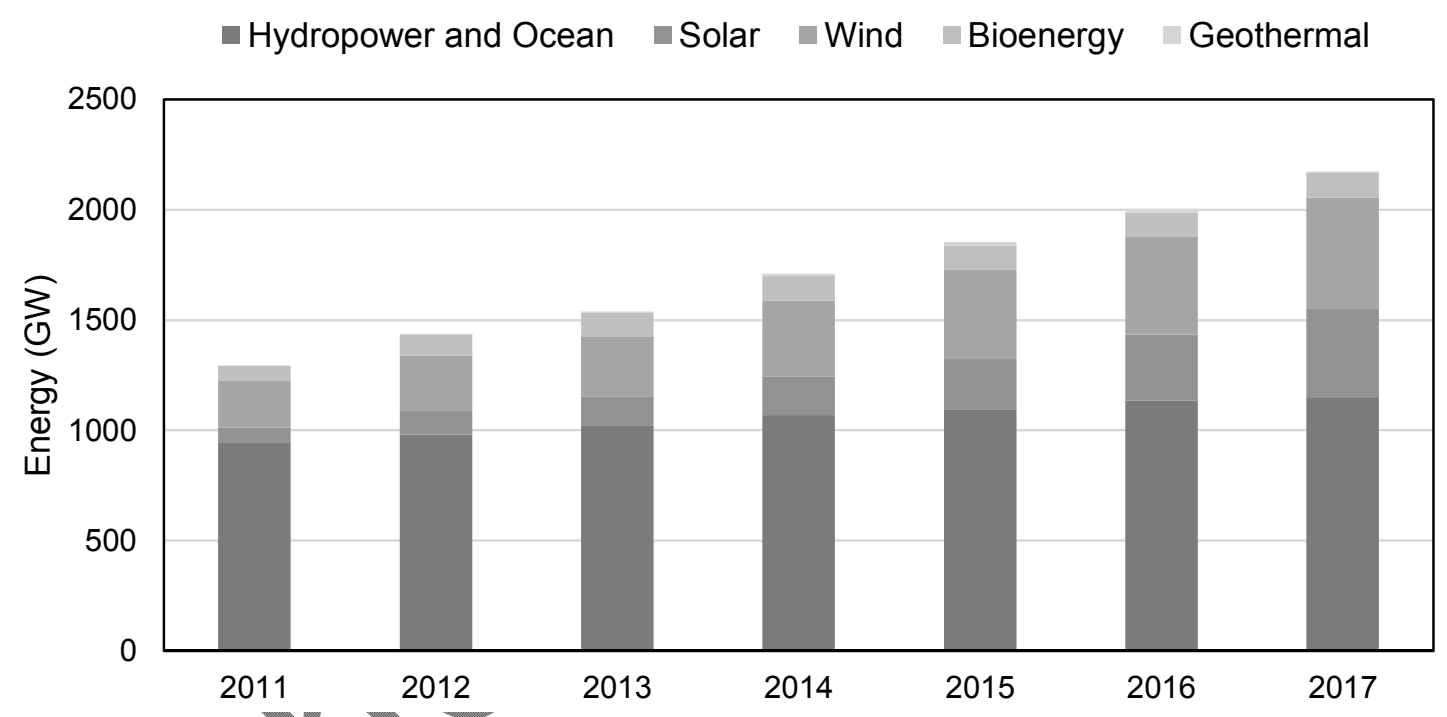

Fig 1. Total renewable power generation capacity, 2011-2017 [10].

Some of the techniques or mechanisms proposed over the last decades to increase the output power generated by the wind turbines are the following:

Vortex stream generating: This technique generates a vortex stream downstream from the turbine rotor, which causes a suction effect on the mass of air located in the windward side of the turbine rotor.

- Constriction of the airflow: This method, based on the Venturi effect, takes advantage of the flow acceleration resulting from the reduction of the cross section. Both natural and artificial obstacles (buildings, mountains, etc.) can lead to increased wind velocity in the air region nearby the edges of the obstacles.

- External flow injection through openings: In this case, a lower pressure region into the wake of the rotor is generated by injecting an external flow through the side openings. The air region close to the rotor in its leeward side reaches lower pressure values in comparison with a bare turbine. As a result, a greater airflow value goes through the rotor turbine. 
One example of vortex stream generating systems is described in Yen [30]. This patent presents a vertical axis wind turbine located at the bottom of a tower, which induces a vortex stream in the wake of the turbine. The air flowing over the external surface of the tower goes in the tower through blades properly orientated to induce an upward stream similar to a tornado inside the tower. The tornado enables the increase of the airflow inlet velocity to the rotor. However, the wind system is not orientated by the free stream direction and hence, a huge amount of wind energy is wasted. Another similar wind energy system thought to improve the performance of wind turbines is presented in Barlot [31]. This patent uses large wind inlet ducts to channel the accelerated airflow to a wind turbine. The invention presents a building structure including a plurality of large-scale channel walls working as canyons for accelerating the wind towards the main building structure. It should be noted that this huge structure requires a high investment, which makes it hardly profitable.

Regarding the systems taking advantage of the airflow contraction, innovative technologies have been particularly proposed for urban environments (Fig. 2). There exist several patented mechanisms aimed at harnessing the increase of wind velocity when the wind cross section diminishes and the streamlines of airflow are strangled. For instance, Gaskell [32] describes a device in which the airflow is accelerated on the external surface of a diffuser and then, it drives a turbine rotor located at the output of the diffuser. This rotor is responsible for inducing a suction stream inside the diffuser, which increases the airflow through a second rotor located at the diffuser inlet. However, the main drawback of this system is that the wake generated by the first rotor reached by the wind negatively affects the performance of the second rotor and therefore, the suction effect weakens.

In several patents $[33,34,35]$, the diffuser is an element used to accelerate the wind stream around the turbine. Accelerated airflow inside diffusers has motivated inventors to set the turbine rotor inside of it as in Visser [36]. In this invention, the rotor turbine is positioned in the duct at a location downstream of the smallest cross-sectional area of the duct so that this will provide the maximum power output. A more turbulent air at the diffuser outlet would benefit the energy efficiency of the turbine. Keeley [37] proposed the use of semi-ringed airfoil instead of diffusers in order to lighten the weight of the system, thus facilitating the system orientation by the predominant wind direction. However, this modification might reduce the airflow going through the turbine. Accordingly, in this invention a dual tip on each rotor blade is proposed to take advantage of a high rotor thrust coefficient, which would provide a reduced coefficient of pressure in the rotor-wake. These elements help to reduce the tip losses by inhibiting wake expansion, but there are variations as in Mansberger [38] where a ring enclosing the rotor turbine was proposed. In addition, this patent not only extracts kinetic energy from the wind, but also thermal energy by reducing the air temperature flowing through the rotor. The ducted rotor technology has been also applied to the design of new aerial vehicle as in $[39,40]$. These types of wind turbines has been also designed to be located on the top part of trucks in order to generate electric energy $[41,42]$.

Other inventors approached the increase of the energy generated by the wind turbine through the modification of the blade geometry [43, 44, 45, 46, 47]. A configurable airfoil system to modify the airfoil with the wind direction has been also suggested [48, 49]. On the other hand, new materials for the blades have been proposed in several inventions in order to extend the turbine lifetime $[50,51,52,53,54]$.

The previous patents exhibited inventions aimed at enclosing horizontal axis turbine rotors; nevertheless, there are other patents in which vertical axis turbine rotors in combination with diffuser are presented, as in Westergaard [55]. This invention is particularly focused on urban locations, where the wind resource is significantly low and the available space is limited. In this line, Reyna [56] designed a vertical axis wind turbine (VAWT) with improved and optimized wind-directing, wind-shaping, and wind-power conversion features. The authors proposed a new geometry for the blades to rise the wind turbine performance with respect to Savonius' wind turbines. Other configurations of vertical axis turbine rotors can be found in [57, 58, 59, 60]. Iqbal [61] presented an invention consisting of a vertical axis wind turbine housed inside a ring with 
side openings for the wind passes. In this invention, all the blades of the turbine are continuously changing their angles, from fully open to fully overlap positions, during each rotation.

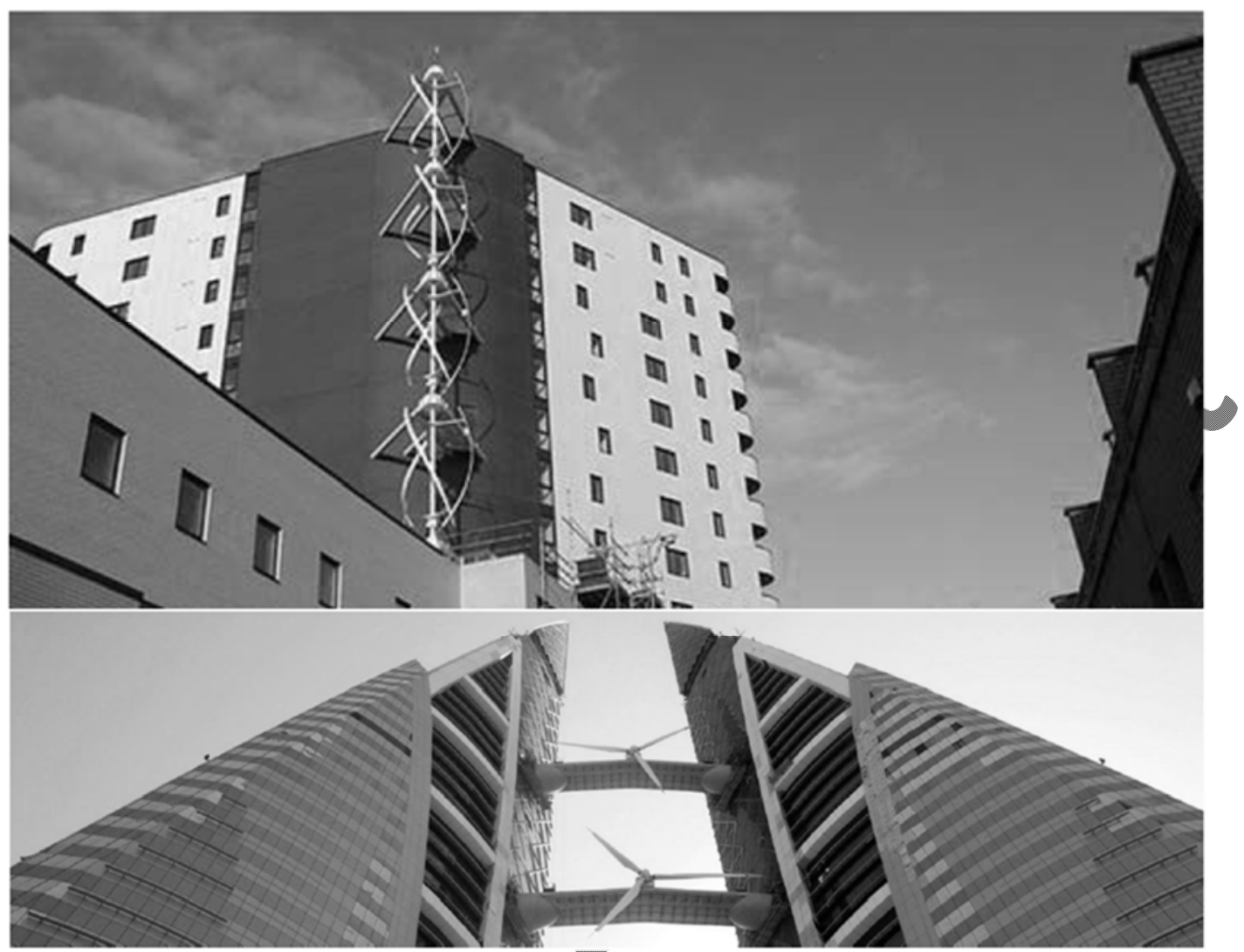

Fig 2. Samples of building-integrated turbine project [22].

Likewise, the external flow injection through openings around the turbine is a mechanism referred to in several patents that is used to amplify the wind turbine performance. Oman [62] describes a system formed by a diffuser with openings acting as inlets for the external air flowing on the surface of the diffuser. The wind turbine is located inside the diffuser, near the inlet. The role of these openings is to delay the separation of the boundary layer from the internal surface of the diffuser, what reduces the diffuser length while keeping the same outlet-to-inlet area ratio. This increases the system performance and reduces the material required for the manufacturing of a prototype. Nevertheless, the stator guides in the windward side of the turbine rotor could be a disadvantage rather than an advantage, as the wake generated would cause random forces on the rotor, which would make the power coefficient of the turbine decrease.

In summary, several shortcomings have been found in today's technologies in relation to the increase of the wind turbine performance:

- An early separation of the boundary layer from the inner surface of the diffuser that diminishes the wind turbine efficiency.

- Some systems lose wind energy since they are not able to self-orientate into the main wind direction.

- Many of the current systems have the turbine rotor in a position where it is reached by a turbulent flow, which ultimately has a negative impact on the system efficiency.

Given this context, the patent here analysed was developed in order to contribute to the topic (Alonso et al. [63]). Thus, with the system described in this paper the authors intend to upgrade the current technology by means of a new design of wind concentrator system. The system consists of two diffusers located one after the other according to the main wind direction, which generates a stronger suction effect on the air mass in the windward side of the rotor located in the 
inlet of the first diffuser. In addition, the radial gap between both diffusers generates a constriction of the external air stream and consequently, a high-speed channel in this region that contributes to increase the suction effect. In order to delay the separation of the boundary layer from the inner surface of the diffuser, semi-spherical grooves similar to those implemented on the golf ball surface were mechanized on the diffuser surface. With this measure, the contact with the surface of the diffusers of a more turbulent and therefore, more energetic, boundary layer, was promoted. Based on its characteristics, the innovative system here presented is expected to be more efficient than those inventions found in the literature so far.

\section{Description of the patented device}

This patent is an innovative solution in the field of the renewable energies aimed at improving the performance of the augmented wind turbine systems. The way the airflow through the turbine is increased is based on the following strategies: (1) guiding of a high speed channel toward the turbine wake; (2) delay of the separation point of the boundary layer flowing on the diffuser inner surfaces; and (3) reduction of the pressure in the air region close to the diffuser outlet. The patented system here described satisfies the following requirements

- It must be capable of housing a horizontal axis turbine.

- It must be self-orientating in order to position the turbine roto in a direction perpendicular to the main wind direction. This allows the collection of a higher amount of energy every moment.

- It must reduce the cut-in speed of the wind turbine. This will extend the amount of locations where installing a wind turbine is profitable, as for instance, the urban environments. Moreover, this will result in a reduction of the energy costs.

- It must have a mechanism to protect the turbine against dangerous wind conditions for the reliability of the system. This mechanism will diminish the acceleration effect provided by the patented system.

- It must heighten the suction effect on the air region close to the turbine inlet.

- The optimization of the current diffusers' geometry is limited by the early separation of boundary layer flowing on the inner surface of diffuser. Therefore, the patented device must attempt to minimize this limitation.

To fulfil these requirements and overcome the described deficiencies of the current systems, this patent integrates the following features:

The diffuser surface has been provided with semi-spherical grooves in order to induce a stronger level of turbulence in the boundary layer flowing on inside surface of diffuser. This will enable the reduction of the diffuser length, keeping the same area ratio between the diffuser outlet and inlet and not increasing the risk of separation of the boundary layer from the inner surface of the diffuser.

- Two different solutions to increase the suction effect on the external air mass close to the turbine inlet. One of them is including at least one ring around the first diffuser outlet that orientates the accelerated air stream on the external surface of the diffuser toward the central region in the turbine wake. Another strategy consists of installing a second coaxial diffuser following the outlet of the first diffuser, thus leaving a radial gap between both diffusers for the generation of a high-speed channel. The application of both methods will ultimately improve the performance of the wind turbine. 
- Two rectangular plates located in the back part of the wind system will enable the system to be self-orientated by the wind the direction always, thus collecting more energy from the wind.

- Several rectangular plates are attached to the external central zone of the diffuser by springs in order to protect the system against extreme wind conditions. These plates divert the external streamlines outwards by increasing the suction effect on them, which reduces the airflow at the turbine inlet as the effect of suction caused by the accelerated streamlines is minimized.

- The diffuser has been designed to house a horizontal axis wind turbine. The rotor of the turbine is located close to the diffuser inlet, where the wind velocity reaches the highest values.

A description of the design of the patented system is included in this manuscript. The evolution of the system design along with the different proposed alternatives are shown in Figs. 3-5. The rotor of the horizontal axis wind turbine (1) is located at the inlet of the first diffuser (2), which is responsible for increasing the airflow through the turbine in the first place. In both surfaces of the diffuser $(3,4)$ grooves with semi-spherical shape (5) have been mechanized, which contribute to generate a more turbulent boundary layer in the air region close to the diffuser surfaces. The higher the level of turbulence in the boundary layer, the more diffictlt it is to separate this from the surface of the diffuser, as a more energetic boundary layer is obtained. This enables the reduction of the diffuser length while keeping the same outlet-to-inlet area ratio, which benefits the diffuser efficiency as the airflow flowing through is accelerated.

Around the central part of the diffuser, a plate belt (6) is integrated to protect the wind turbine operation against dangerous wind conditions. Thus, in order to reduce the negative effect of these conditions, several rectangular plates are attached to the diffuser by means of a rotation axis and springs. The plates will keep parallel tothe diffuser surface if the wind velocity does not exceed a critical value, as the elastic forces generated by the springs are higher than the suction forces induced by the pressure gradients between both surfaces of plates. However, if the wind velocity is too high the suction force turns the plates around their rotation axis so that they are positioned at a certain angle with respect to the external surface of the diffuser.

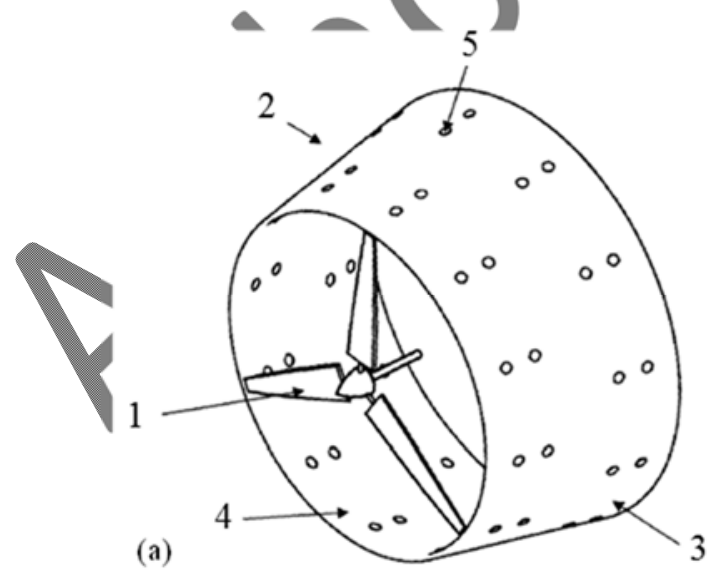

(b)

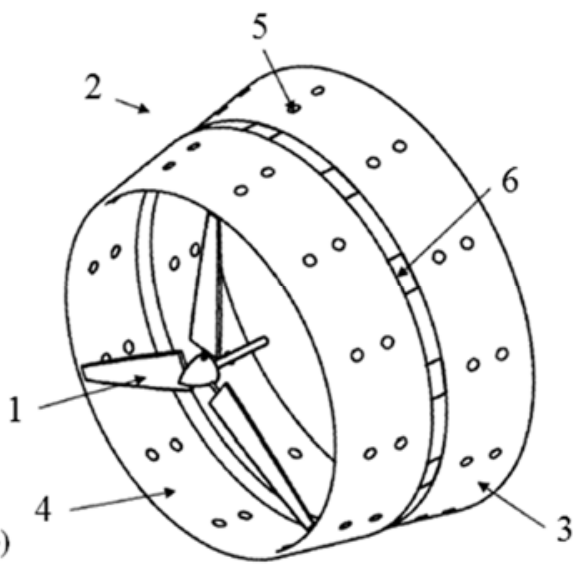

Fig 3. (a) First diffuser with semi spherical grooves on the surface. (b) First diffuser with plate belt to protect the system against dangerous wind velocities.

Two alternatives are proposed in the patent for reducing the pressure at the air region nearby the diffuser outlet (Fig. 4). Firstly, a flanged brim structure (7) is located around the diffuser outlet so that the high-speed air stream flowing on the external surface of the diffuser hits against the 
brim, thus raising the level of turbulence in its leeward side. The other alternative consists of positioning at least one ring (8) around the diffuser outlet to guide the external airflow from the diffuser outlet toward the wake. Deflecting the high velocity external flow in the wake of the turbine rises the suction effect on the air mass close to the diffuser inlet and as a result, the airflow passing through the rotor of turbine.
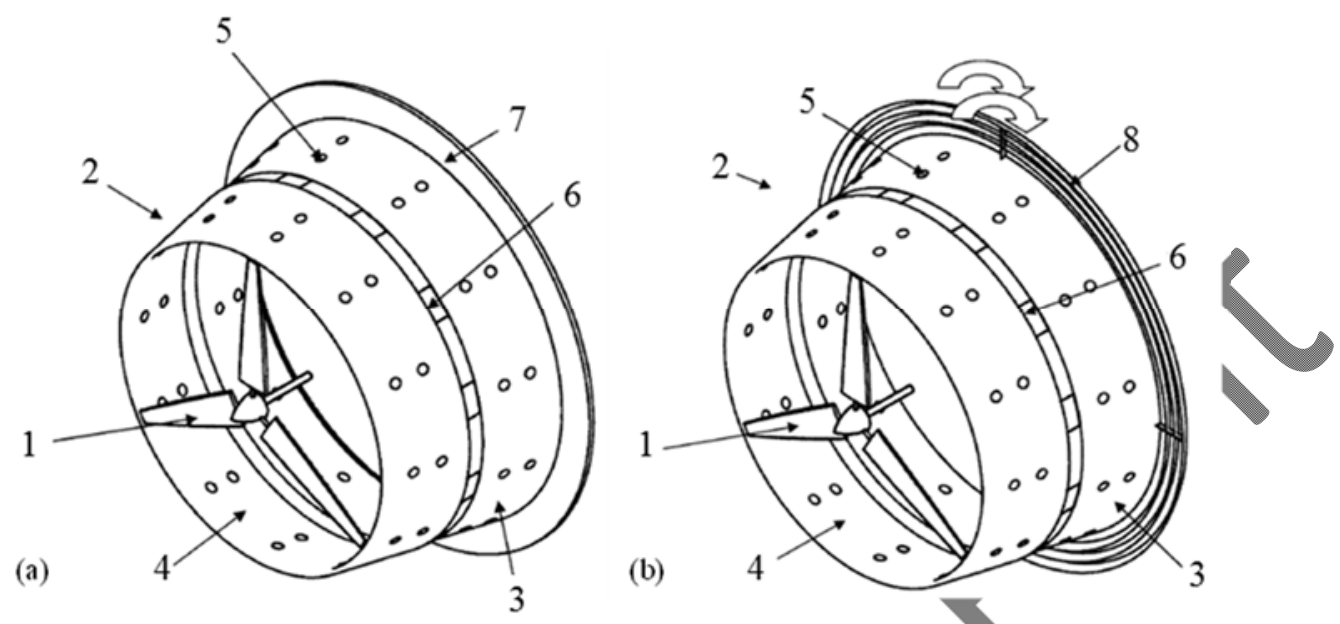

Fig 4. (a) Diffuser with brim around the diffuser outlet. (b) Diffuser with three concentric rings around the diffuser outlet.

The full device also includes a second diffuser (9) located behind the first diffuser and orientated by the predominant wind direction (Fig. 5). This second diffuser also contributes to reduce the air pressure in the wake region caused by the turbine, which eventually increases the airflow through the rotor. On the other hand, two rectangular plates (10) are attached to the second diffuser outlet with the aim of self-orientating the system by the predominant wind direction every moment. The accelerator system of the airflow is supported by a post (11). This post includes a bearing that allows the wind accelerator system to rotate.

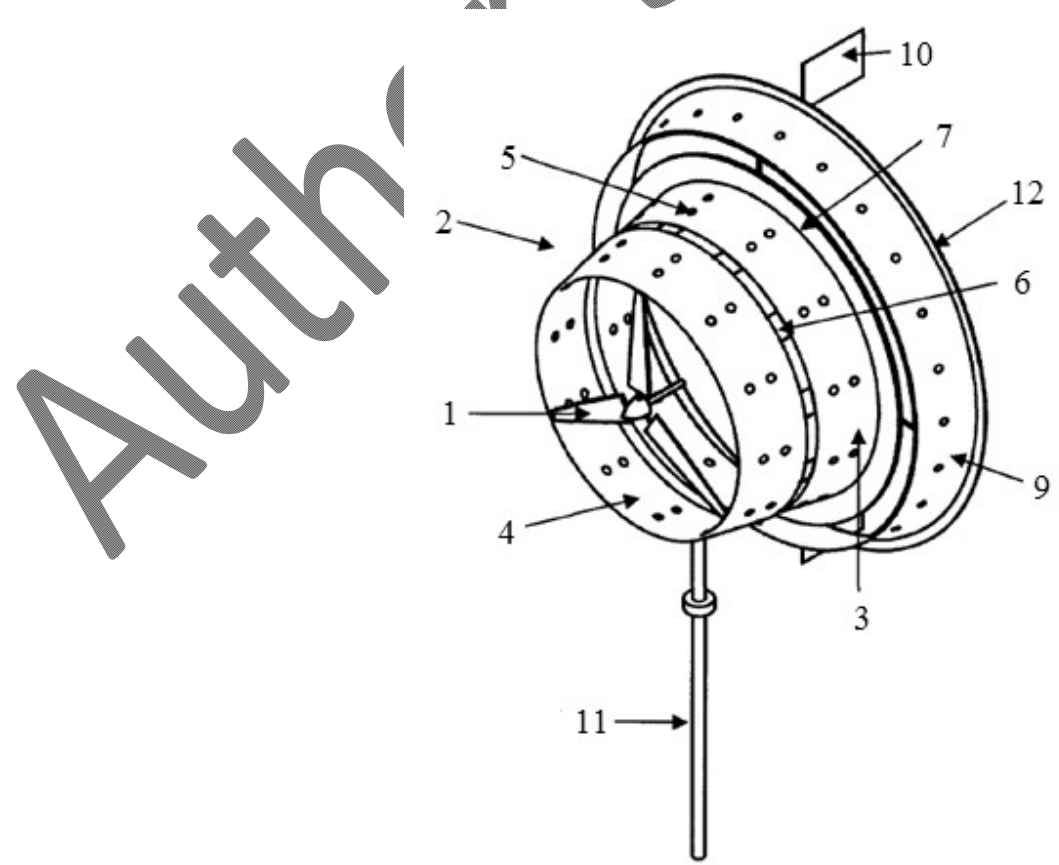

Fig 5. Elements of the full system.

\section{Geometry and materials specifications for the wind system}


As for the materials used in the manufacturing of the patented device, they must be stiff, light and tough. A high enough stiffness prevents the modification of the geometry of the different elements of the device by the wind loads, which is necessary to accomplish the goal of the wind system. In addition, the structure must be light enough as to properly self-orientate by the predominant wind direction. Finally, the device must be tough enough as to withstand extreme wind conditions. Therefore, the material selection will depend on the wind conditions existing in the location where the wind turbine is installed. In view of these requisites, the following materials might be suitable for the manufacturing of the system: aluminium alloys, fiberglass reinforced with polyester resin, fiberglass reinforced with epoxy resin, carbon fiber or aramides and composite materials such as wood-epoxy or wood-fiber-epoxy. Structural steel can be used in order to manufacture the post in charge of bearing the weight of the airflow accelerator system.

The geometry of the device has been defined based on the numerical methods solved, and is aimed at housing a three-bladed rotor of $0.9 \mathrm{~m}$ diameter. The first diffuser has an inlet diameter of $1 \mathrm{~m}$, an outlet diameter of $1.2 \mathrm{~m}$ and a length of $0.6 \mathrm{~m}$. The belt of plates, designed toprotect the device against dangerous wind conditions, is composed of 12 rectangular plates whose maximum opening angle is $40^{\circ}$. The axial distance between the second diffuser inlet and the first diffuser outlet is $0.05 \mathrm{~m}$, whereas the horizontal length of the second diffuser is $0.2 \mathrm{~m}$. As for the second diffuser, the inlet diameter is $1.55 \mathrm{~m}$ and the outlet diameter is $1.7 \mathrm{~m}$. The rectangular plate located in the second diffuser (60 in Fig. 5) is $0.2 \mathrm{~m}$ wide and $0.3 \mathrm{~m}$ high.

The use of coaxial rings is an alternative to the brim located in the first diffuser outlet. Three rings have been proposed for the prototype. The slope angle of the coaxial rings with respect to the diffusor axis is $30^{\circ}$, and the minimum radial gap between the_coaxial rings is $20 \mathrm{~mm}$.

\section{Numerical analysis of the patented device using FEM}

\subsection{Mathematical approach}

The design and performance evaluation of the wind system have been carried out by using CFD (Computation Fluid Dynamics) code, FLUENT. This technique has been widely applied and validated in different studies focused on the design of new models of ducted wind turbines [64, $65,66,67,68]$. With this aim, the Reynolds-averaged Navier-Stokes (RANS) equations along with the $k-\varepsilon$ turbulence model were solved by applying the finite-volume method $[69,70,71]$. Enhanced wall functions were used to model the airflow behaviour in the air region close to the solid surfaces. In this region, a finer mesh was built to more accurately estimate the variable values. As for the mathematical approach, second-order schemes were applied to spatially discretize the governing equations $[72,73]$ :

$$
\begin{gathered}
\frac{\partial \bar{u}_{l}}{\partial x_{i}}=0 \\
\frac{\partial}{\partial t}\left(\rho \bar{u}_{l}\right)+\frac{\partial}{\partial x_{j}}\left(\rho \bar{u}_{\imath} \bar{u}_{\jmath}\right)=-\frac{\partial \bar{p}}{\partial x_{i}}+\frac{\partial}{\partial x_{j}}\left[\mu\left(\frac{\partial \bar{u}_{l}}{\partial x_{j}}+\frac{\partial \bar{u}_{j}}{\partial x_{i}}\right)-\rho \overline{u_{\imath}^{\prime} u_{\jmath}^{\prime}}\right]
\end{gathered}
$$

The term $-\rho \overline{u_{\imath}^{\prime} u_{\jmath}^{\prime}}$ is a turbulent stress or Reynolds stress and states the correlations among the fluctuating velocity components. Besides, this term represents a new unknown in the system of equations to be solved. Accordingly, the turbulence standard $k-\varepsilon$ model was used to close the equations system, as this includes this term in its transport equations (equations 3 and 4). More detailed information about constants or closure coefficients can be found in [74, 75]. 


$$
\begin{gathered}
\frac{\partial k}{\partial t}+\bar{u}_{J} \frac{\partial k}{\partial x_{j}}=v_{T}\left[\left(\frac{\partial \bar{u}_{\imath}}{\partial x_{j}}+\frac{\partial \bar{u}_{j}}{\partial x_{i}}\right) \frac{\partial \bar{u}_{\imath}}{\partial x_{j}}\right]-\varepsilon+\frac{\partial}{\partial x_{j}}\left[\left(v+\frac{v_{T}}{\sigma_{k}}\right) \frac{\partial k}{\partial x_{j}}\right] \\
\frac{\partial \varepsilon}{\partial t}+\bar{u}_{J} \frac{\partial \varepsilon}{\partial x_{j}}=C_{\varepsilon 1} v_{T} \frac{\varepsilon}{k}\left[\left(\frac{\partial \bar{u}_{\imath}}{\partial x_{j}}+\frac{\partial \bar{u}_{j}}{\partial x_{i}}\right) \frac{\partial \bar{u}_{\imath}}{\partial x_{j}}\right]-C_{\varepsilon 2} \frac{\varepsilon^{2}}{k}+\frac{\partial}{\partial x_{j}}\left[\left(v+\frac{v_{T}}{\sigma_{\varepsilon}}\right) \frac{\partial \varepsilon}{\partial x_{j}}\right]
\end{gathered}
$$

The air domain was divided into two shapes of control volumes, tetrahedral cells in the air region far from the wind system and wedge cells in the boundary layer regions. Three kinds of boundary conditions were set to solve the model: inlet velocity, wall and outlet pressure. For the inlet velocity, the following parameter values were defined: uniform velocity of $2 \mathrm{~m} / \mathrm{s}$, turbulence intensity of $5 \%$ and viscosity ratio of 10 . Most of three-bladed horizontal-axis wind turbines have a cut-in velocity higher than $2 \mathrm{~m} / \mathrm{s}$. The wall was defined as a no slip wall in terms of shear. As for the boundary condition defined as outlet pressure, both the relative pressure and the normal gradients of all variables were set equal to zero.

\subsection{Results}

In Fig. 6, the geometry of the patented device is presented as defined by the numerical model. As shown in Fig. 6, the post and the self-orientating system were not included. This is because they do not only significantly affect the performance of the system but also because their inclusion would demand more computational resources. For similar computational reasons, the rotor of the wind turbine was not included in the geometry either, as it is not necessary to evaluate if the characteristics of the airflow reaching the rotor are improved by means of the patented system. The geometry shown in Fig. 6 was extracted from the fluid domain in order to solve the CFD model.

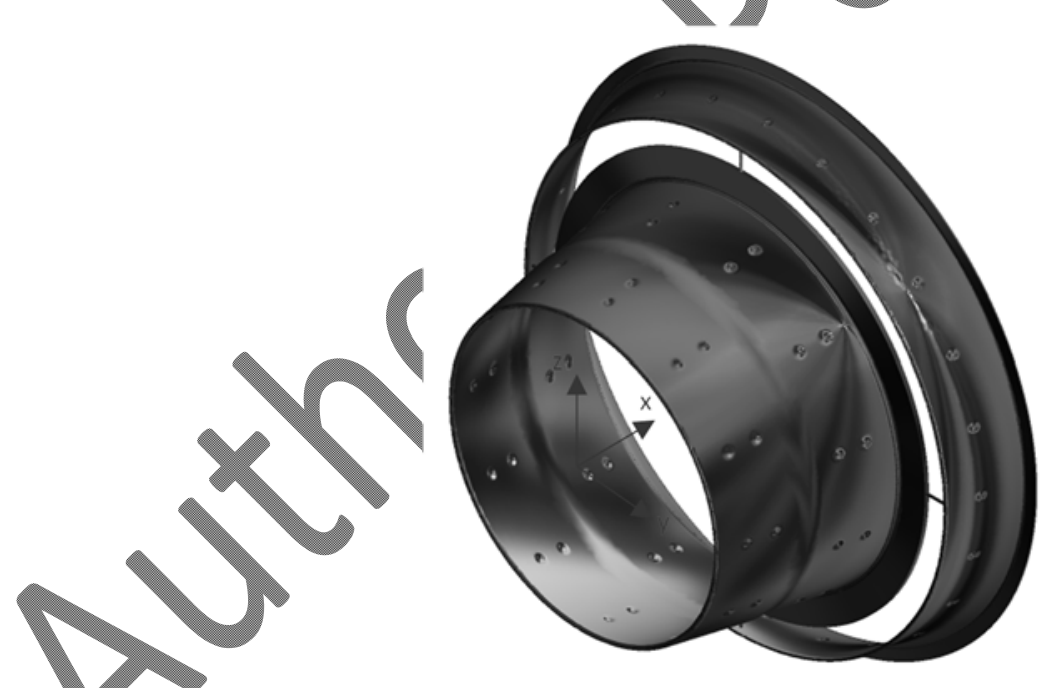

Fig 6. Geometry of patented wind system by numerical simulation (d).

Regarding the results obtained, Fig. 7(a) shows the contour plot of velocity, where it can be noticed how the wind velocity exceeds the $2.8 \mathrm{~m} / \mathrm{s}$ in the air region close to the first diffuser inlet. The air region in the leeward side of the brim exhibits the lowest velocity values, as it was expected, thus indicating that the brim generates a turbulent region in that side. In fact, Fig. 7(b) shows the vortexes caused by the brim around the outlet of the first diffuser. According to [76], these vortexes contribute to increase the airflow in the diffuser inlet. The goal of the second diffuser is also achieved, as a high-speed channel is generated in the air region close to its inner surface (Fig. 7(a)), thus increasing the suction effect on the air mass near the inlet. 


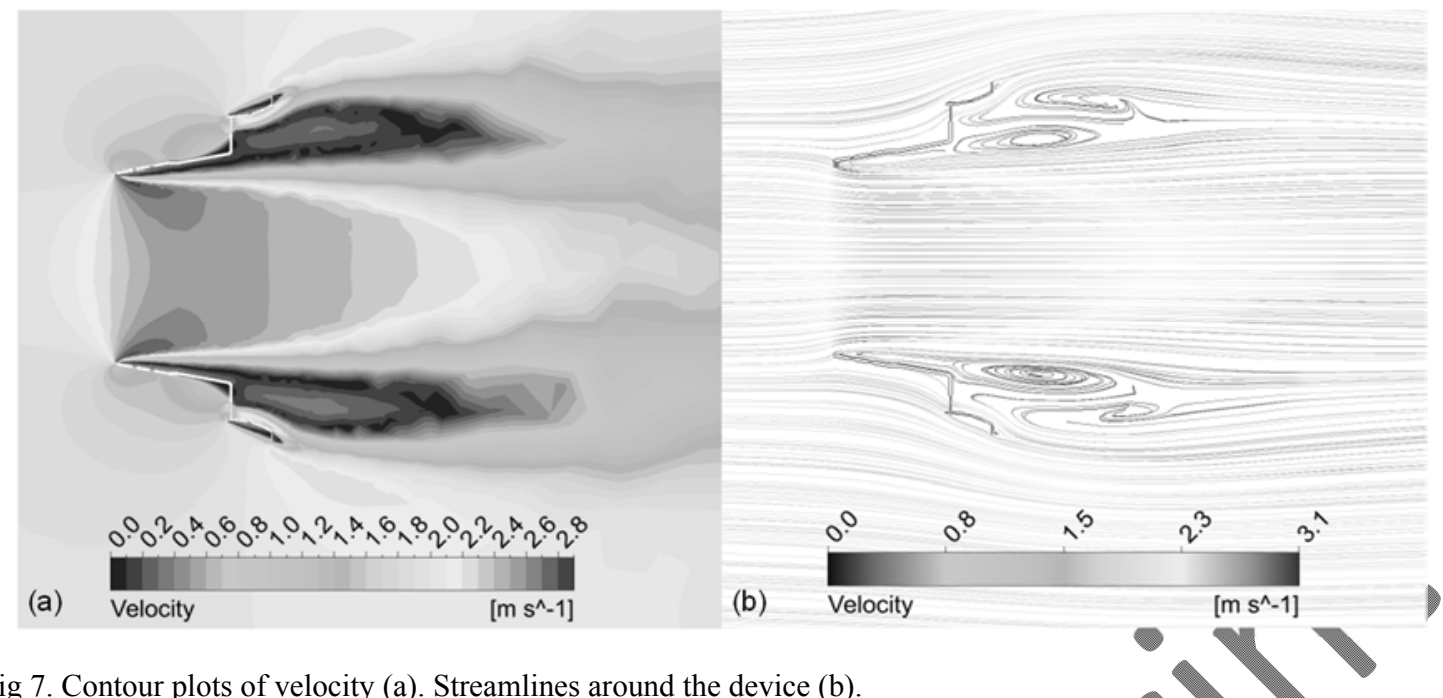

Fig 7. Contour plots of velocity (a). Streamlines around the device (b).

On the other hand, a subatmospheric pressure is obtained in the air region within the diffuser (Fig 8), which causes a suction effect on the air near the inlet. This effect increases the airflow through the wind turbine and hence, the power generated. In the windward side of the brim, the pressure reaches the highest values due to the impact of the streamlines flowing on the external surface of the diffuser. The pressure values are also relatively high along the external surface of both diffusers as they deflect the streamlines from the free stream. The subatmospheric pressure values caused within the first diffuser are extended downstream by means of both the brim and the second diffuser. The pressure gradient between the air regions close to both diffusers surfaces induces forces that are driven toward the diffusers axis. Therefore, the surface of both diffusers must be tough enough as to resist these forces in extreme wind conditions.

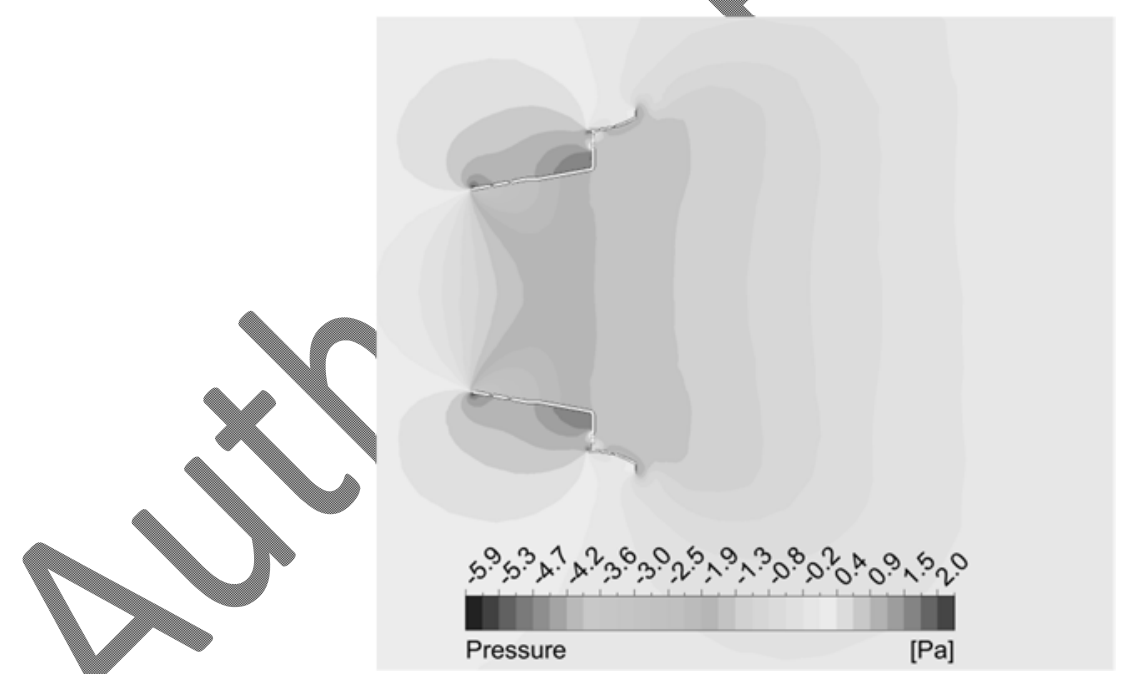

Fig 8. Contour graphs of pressure.

In Fig. 9, the ratio of the wind velocity inside the wind system to the free stream velocity is represented as a function of the distance along the horizontal axis (x-axis in Fig. 9) for five different radial positions from the rotor axis. It can be seen how the airflow velocity increases with the distance from the rotor axis. On the other hand, the maximum ratio of velocities is given in a position further away from the inlet as the rotor axis gets closer (Fig. 9). The maximum ratio of velocity exceeds 1.4 and it is obtained at $0.09 \mathrm{~m}$ from the diffuser inlet. Therefore, the turbine rotor should be located at this position. 


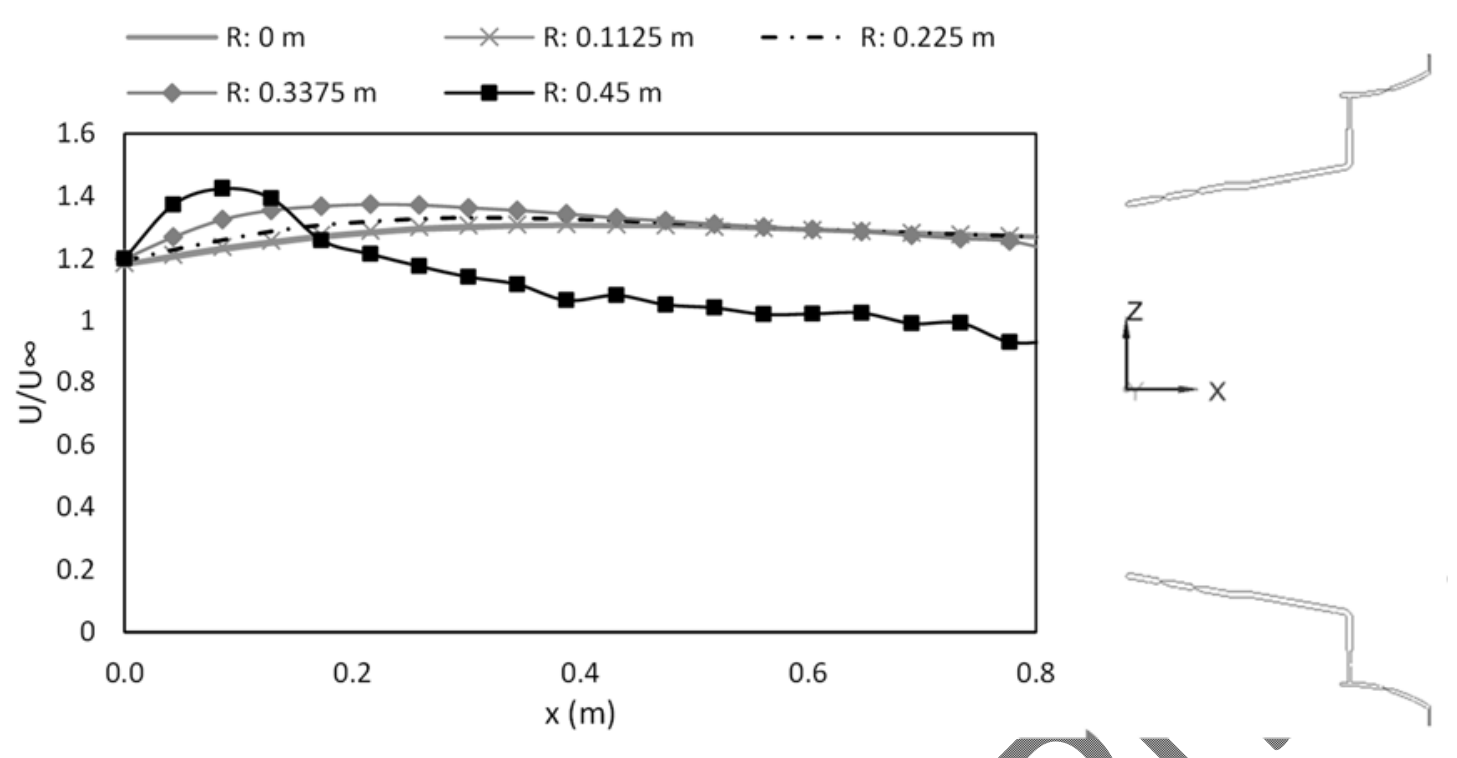

Fig 9. Variation of ratio of velocity inside the wind system along the x-axis for five radial positions.

\section{Conclusions}

In this paper, a patented device aimed at improving the performance of horizontal axis wind turbines by means of an airflow accelerator system based on the diffuser technology has been analysed. This wind system is particularly suitable for locations such as urban environments, where the wind resource is rather low, as it would make possible the reduction of the turbines cutin velocity indicated in the manufacturer's data sheet. Thus, according to the results of the numerical simulation, the wind system is able to increase the airflow velocity in the region closest to the first diffuser inlet. The airflow gain through the turbine rotor is achieved by generating a region of sub atmospheric pressure within the diffuser. To do this, different techniques have been used such as the brim or the gap between the two diffusers. The semi-spherical grooves mechanized on the diffuser surfaces also help to intensify this effect.

The patented device here defined presents new elements as compared to other systems based on the current technology. Thanks to these elements, the turbine output power can be raised, thus enabling its use in areas where the wind resource is not high enough. Particularly, three new elements make this possible: the coaxial rings, to orientate the streamlines from outside of the system toward the turbine wake; the second diffuser, to increase the suction effect on the air mass close to the inlet; and the semi-spherical grooves on the diffuser surfaces, to enable a more turbulent layer flowing on them.

The coaxial rings installed in the first diffuser outlet are a new element that had not been included in previous wind turbine models. They increase the suction effect on the external air mass close to the turbine inlet and consequently, induce a rise of airflow going through the turbine rotor. Another new element proposed to satisfy the same goal is the second coaxial diffuser located downwind following the first diffuser. The diffuser presented in this work shows a significant difference on its surface with respect to the preceding ones. It exhibits numerous semi-spherical grooves on both surfaces, which reduces the risk of separation of the boundary layer from the inner surface of the diffuser. This element enables the design of diffusers with higher divergence angle while keeping the same length, which could improve the wind turbine performance up to a certain value. As this element allows to reduce the diffuser length and reach a specific outlet and inlet area ratio, the material required for the manufacturing of the diffuser will be less. The validity of the present patent has been shown through numerical simulation; however, experimental tests would contribute to improve the knowledge about the device performance. 


\section{CURRENT \& FUTURE DEVELOPMENTS}

According to the results from the numerical simulation, the airflow acceleration system for wind turbines shows a good performance, as a rise of the airflow going through the turbine rotor has been obtained. However, the effect of wind conditions such as wind direction or turbulence intensity should be further studied in order to assess how the wind turbine efficiency is affected by these factors. In the future, an experimental test campaign will be carried out in a wind tunnel test to analyse the behaviour of the patented device and modify some details if it is necessary. Furthermore, these experimental results will enable us to better set the parameters of the numerical setup.

\section{CONSENT FOR PUBLICATION}

Not applicable.

\section{CONFLICT OF INTEREST}

The authors declare no conflict of interest, financial or otherwise.

\section{Acknowledgements}

This work was supported by the OASIS Research Project that was cofinanced by CDTI (Spanish Science and Innovation Ministry) and developed with the Spanish companies: Iridium, OHL Concesiones, Abertis, Sice, Indra, Dragados, OHL, Geocisa, GMV, Asfaltos Augusta, Hidrofersa, Eipsa, PyG, CPS, AEC and Torre de Comares Arquitectos S.L and 16 research centres. The authors also acknowledge the partial funding with FEDER funds under the Research Project FC15-GRUPIN14-004. Finally, we also thank Swanson Analysis Inc. for the use of ANSYS University Research programs as well as the Workbench simulation environment.

\section{References}

[1] Rosales-Asensio E, Borge-Diez D, Blanes-Peiró J-, Pérez-Hoyos A, Comenar-Santos A. Review of wind energy technology and associated market and economic conditions in Spain. Renewable Sustainable Energy Rev 2019:415-427.

[2] Elshurafa, A.M., Farag, H.M., Hobbs, D.A. Blind spots in energy transition policy: Case studies from Germany and USA. Energy Reports 2019; 5:20-28

[3] Blazquez J, Fuentes-Bracamontes R, Bollino CA, Nezamuddin N. The renewable energy policy Paradox. Renewable Sustainable Energy Rev 2018;82:1-5.

[4] World Energy Council. World energy resources. World Energy Resources 2016.

[5] Yu HJJ, Popiolek N, Geoffron P. Solar photovoltaic energy policy and globalization: A multiperspective approach with case studies of Germany, Japan, and China. Prog Photovoltaics Res Appl 2016;24(4):458476.

[6] Giacomarra M, Bono F. European Union commitment towards RES market penetration: From the first legislative acts to the publication of the recent guidelines on State aid 2014/2020. Renewable Sustainable Energy Rev 2015;47:218-232.

[7] Kozlova M. Real option valuation in renewable energy literature: Research focus, trends and design. Renewable Sustainable Energy Rev 2017;80:180-196.

[8] Serrano-González J, Lacal-Arántegui R. Technological evolution of onshore wind turbines-a marketbased analysis. Wind Energy 2016;19(12):2171-2187. 
[9] Tummala A, Velamati RK, Sinha DK, Indraja V, Krishna VH. A review on small scale wind turbines. Renewable Sustainable Energy Rev 2016;56:1351-1371.

[10] http://www.irena.org/newsroom/pressreleases/2018/Apr/Global-Renewable-Generation-Continues-its Strong-Growth-New-IRENA-Capacity-Data-Shows.

[11] Global Wind Energy Council. Greenpeace International. Global wind energy outlook 2014; October 2014.

[12] Alkhalidi MA, Al-Dabbous SK, Neelamani S, Aldashti HA. Wind energy potential at coastal and offshore locations in the state of Kuwait. Renew Energy 2019:529-539.

[13] Wang Y-, Walter RK, White C, Farr H, Ruttenberg BI. Assessment of surface wind datasets for estimating offshore wind energy along the Central California Coast. Renew Energy 2019:343-353.

[14] Edesess AJ, Kelliher D, Borthwick AGL, Thomas G. Improving global accessibility to offshore wind power through decreased operations and maintenance costs: A hydrodynamic analysis. Energy Procedia 2017; 138: 1055-1060.

[15] Lutzeyer S, Phaneuf DJ, Taylor LO. The amenity costs of offshore wind farms: Evidence from a choice experiment. Energy Economics 2018; 72: 621-639.

[16] Kausche M, Adam F, Dahlhaus F, Großmann J. Floating offshore wind - Economic and ecological challenges of a TLP solution. Renewable Energy 2018; 126: 270-280.

[17] Chrysochoidis-Antsos N, Van Wijk A. Wind flow potential above noise barriers for urban wind turbine applications near highways. 7th European and African Conference on Wind Engineering, EACWE; Liege; Belgium; 4 July 2017 through 7 July 2017.

[18] Manwell JF, McGowan JG, Rogers AL. $2^{\text {nd }}$ ed. Wind Energy Explained: Theory, Design and Application. John Wiley \& Sons: Chichester, UK 2010.

[19] Kumar R, Raahemifar K, Fung AS, A critical review of vertical axis wind turbines for urban applications. Renewable Sustainable Energy Rev 2018; 89:281-291.

[20] Kefi S, Joneja A, K.T. Tse T, Li S. Channel geometry optimization for vertical axis wind turbines in skyscrapers. Comput -Aided Des Appl 2018; 15(2):211-218.

[21] Abohela I, Hamza N, Dudek S. Effect of roof shape, wind direction, building height and urban configuration on the energy yield and positioning of roof mounted wind turbines. Renew Energy 2013; 50:1106-1118.

[22] Bobrova, D. 2015. Building-integrated wind turbines in the aspect of architectural shaping. Procedia Engineering 117(1),pp. 409-415.

[23] Kent CW, Grimmond S, Gatey D, Hirano K. Urban morphology parameters from global digital elevation models. Implications for aerodynamic roughness and for wind-speed estimation. Remote Sens Environ 2019; 221:316-339.

[24] Kent CW, Grimmond S, Gatey D. Aerodynamic roughness parameters in cities: Inclusion of vegetation. J Wind Eng Ind Aerodyn 2017; 169:168-176.

[25] Cace, J., Horst, E., Syngellakis, K., Niel, M., Clement, P., Heppener, R., Peirano, E., 2007. Urban wind turbines. Guidelines for small wind turbines in the built environment 2016, 41.

[26] Dilimulati, A., Stathopoulos, T., Paraschivoiu, M. 2018. Wind turbine designs for urban applications: A case study of shrouded diffuser casing for turbines. Journal of Wind Engineering and Industrial Aerodynamics 175, pp. 179-192.

[27] Rezaeiha A, Montazeri H, Blocken B. Towards optimal aerodynamic design of vertical axis wind turbines: Impact of solidity and number of blades. Energy 2018: 1129-1148. 
[28] Rezaeiha A, Kalkman I, Montazeri H, Blocken B. Effect of the shaft on the aerodynamic performance of urban vertical axis wind turbines. Energy Convers Manage 2017; 149:616-630.

[29] Tutunaru C. Vertical axis wind turbine. US20180100483 (2018).

[30] Yen, J.T. Tornado-type windturbine. US4070131 (1978).

[31] Barlot, J. Wind energy system including canyon structure. WO2017100951 (2017).

[32] Gaskell, C.N. Ducted wind turbine. US7018166 (2006).

[33] 尹小林赵海洋. Multi -functional genertrix of duct increase convenient to carry. CN207777057U (2018).

[34] Sutz, R.K., Jenkins, P.E. Multiple - blade wind machine with shrouded rotors. US10066597 (2018).

[35] Saddoughi, S.G., Boespflug, M.P., Idelchik, M.S., Bennett, G.A. Apparatus and method for aerodynamic performance enhancement of a wind turbine. US20170211545 (2017).

[36] Visser, K.D. Aft rotor ducted wind turbine. US20170138337 (2017).

[37] Keeley, W.S. Fluid turbine semi-shroud and associated rotor blade dual-winglet design. WO2018093398 (2018).

[38] Mansberger, L.L. Thermodynamic wind turbine. US20170314529 (2017).

[39] Tseng, J., Edwards, B. Ducted rotor unmanned aerial vehicles. US10017249 (2016).

[40] Gaither, G. Wind turbine systems and air channels in vehicles for enhancing energy generation, cooling, and aerodynamics. US 20170082092 (2017).

[41] Schlosser, R. Vehicle with a device for generating wind energy.

[42] 彦七 高橋彦七 高橋. The wind turbine generator with a vehicle. JP6120193 (2017).

[43] Fujioka, H., Sato, K. Wind turbine blade and wind turbine power generating apparatus, and method of producing or retrofitting wind turbine blade. US 20160348643 (2016).

[44] Sorondo Zabala, E., Erauzquin Bilbao, M.E., Carretero Villanueva, J.L. Method for optimizing the efficiency of wind turbine blades. EP 2674613 (2013).

[45] Tobin, J.R., William, M.G., Herr, S. Tip extensionassembly for a wind turbine rotor blade. US $20170101979(2017)$

[46] Tobin, J.R., Riddell, S.G., Booth, M.C. Attachment method and system to install components, such as vortex generators, to a wind turbine blade. US20160327021 (2016).

[47] McMahon, E., Hoffman, L. High torque wind turbine blade, turbine, and associated systems and methods. US 9797370 (2017).

[48] Grigg, C. Vertical axis wind turbine with configurable airfoils. US20170051720 (2017).

[49] Piskorz, W., Piskorz, T.T., Piskorz, I. Wind turbine with rotational air guides. US20180003152 (2018).

[50] Yarbrough, A.A., Caruso, C.D. Wind turbine rotor blade components formed from pultruded hybridresin fiber-renforced composites. US20170082089 (2017).

[51] Yarbrough, A.A., Caruso, C.D. Spar cap for a wind turbine rotor blade formed from pre-cured laminate plates of varying thicknesses. US20170002791 (2017).

[52] Yarbrough, A.A., Caruso, C.D., Kasperski, D.J. Corrugated pre-cured laminate plates for use within wind turbine rotor blades. US20170002792 (2017). 
[53] Nomen, V.M., Puig, J.M. Lightning protection system for wind turbine blades with an effective injection area to carbon fiber laminates and a balanced lightning current and voltage distribution between different conductive paths. US20160369781 (2016).

[54] Hayden, P.T., Whiley, D.A. Wind turbine blade. US20160333849 (2016).

[55] Westergaard, C.H., Hjort, S. Wind power generating rotor with diffuser or diverter system for a wind turbine. WO2018176004 (2018).

[56] Reyna, S.J., Conarro, P.R. Vertical axis wind turbine. US20160377053 (2016).

[57] Baxter, R. Wind turbine. US20180135599 (2018).

[58] West, R.R. Wind turbine system. US20160208774 (2016).

[59] Rao, V. Wind Turbine. US20160230742 (2016).

[60] Elayyan, M.M.Y. Wind Turbine. US20180038344 (2018).

[61] Iqbal, M.M. Self-directed vertical axis wind turbine. US9797372 (2015).

[62] Oman, R.A., Foreman, K.M. Variable stator, diffuser augmented wind turbine electrical generation system. US4075500 (1978).

[63] Alonso Estébanez, A., Castro Fresno, D., Pascual Muñoz, P., Delchoz Diaz, J.J., Álvarez Rabanal, F.P. Acceleration system airflow for wind turbines. ES2514990 (2015).

[64] Khamlaj TA, Rumpfkeil MP. Analysis and optimization of ducted wind turbines. Energy 2018;162:1234-1252.

[65] Harnessing marine energy by horizontal axis matine turbines. Proceedings of 2015 12th International Bhurban Conference on Applied Sciences and Technology, IBCAST 2015; 2015.

[66] Zanforlin S, Letizia S. Effects of upstream buildings on the performance of a synergistic roof-anddiffuser augmentation system for cross flow wind turbines. J Wind Eng Ind Aerodyn 2019;184:329-341.

[67] Agha A, Chaudhry HN, Wang F. Diffuser Augmented Wind Turbine (DAWT) technologies: A review. Int J Renew Energy Res 2018;8(3):1369-1385.

[68] Analysis of diffuser augmented wind turbine (DAWT) with flange and curved interior using CFD. AIP Conference Proceedings; 2018.

[69] Zhu H, Hao W, Li C, Ding Q. Numerical study of effect of solidity on vertical axis wind turbine with Gurney flap. J Wind Eng Ind Aerodyn 2019; 186:17-31.

[70] Anbarsooz M, Amìi M, Rashidi I. A novel curtain design to enhance the aerodynamic performance of Invelox: A steady-RANS numerical simulation. Energy 2019;168:207-221.

[71] Optimization of a Flanged DAWT Using a CFD Actuator Disc Method. Springer Proceedings in Mathematics and Statistics; 2018.

[72] Andersson B, Andersson R, Hakansson L, Mortensen M, Rahman S, Berend VW. $1^{\text {st }}$ ed. Computational fluid dynamics for engineers. Cambridge University Press, New York, USA 2012.

[73] Tu, J.; Yeoh, G.H.; Liu, C. Computational Fluid Dynamics: A Practical Approach, $2^{\text {nd }}$ ed. Burlington: Butterworth-Heinemann, Waltham, MA, USA 2013.

[74] ANSYS User Manual (2017). ANSYS, Inc. Canonsburg, PA.

[75] Moukalled F, Mangani L, Darwish M. The Finite Volume Method in Computational Fluid Dynamics: An Advanced Introduction with OpenFOAM ${ }^{\circledR}$ and Matlab ${ }^{\circledR}$. Springer International Publishing: Switzerland. 2016. 
[76] Ohya, Y., Miyazaki, J., Göltenbott, U., Watanabe, K. 2017. Power Augmentation of Shrouded Wind Turbines in a Multirotor System. Journal of Energy Resources Technology, Transactions of the ASME, 139 (5), art. no. 051202.

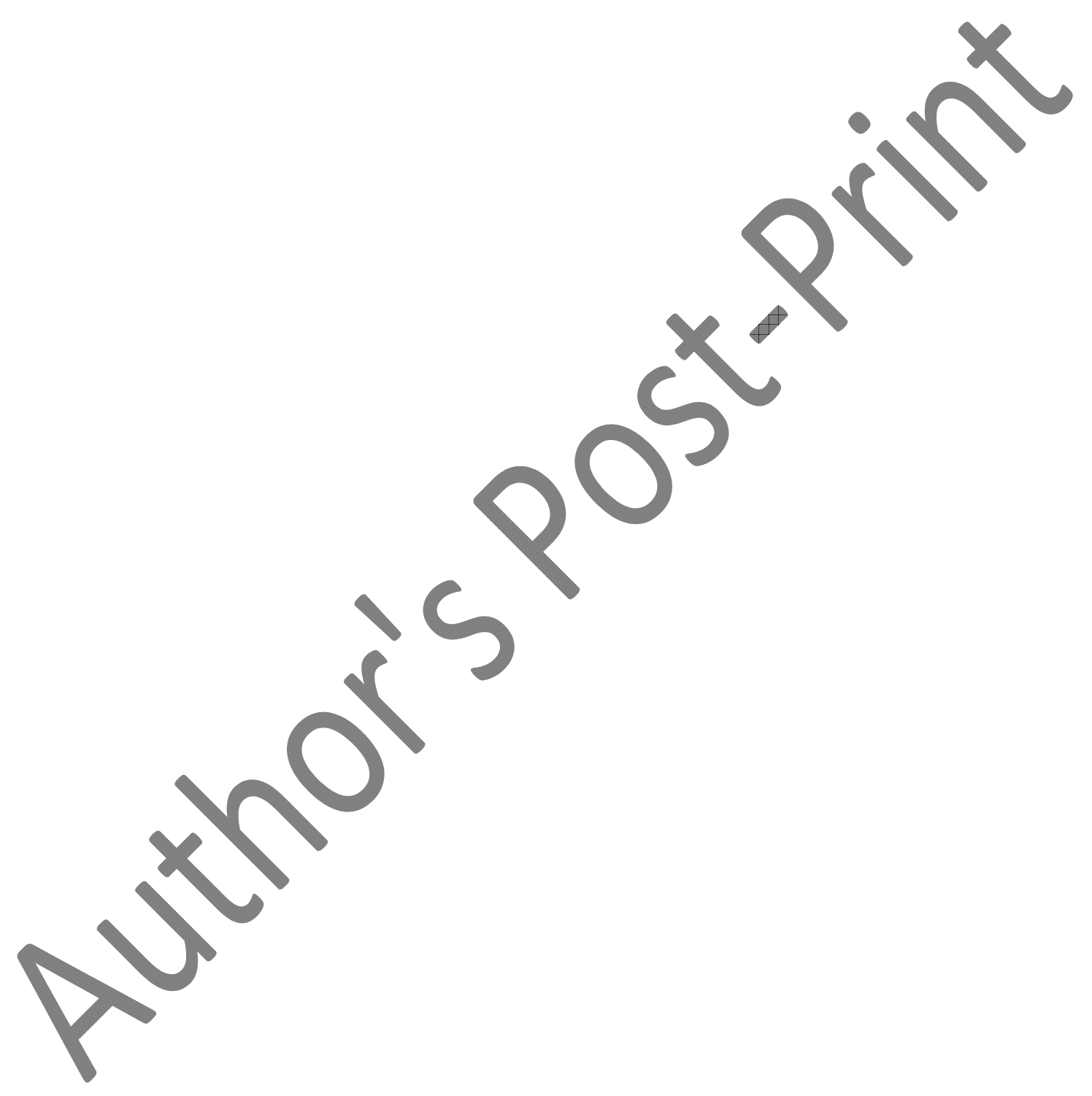

